\section{The labyrinth method of comparing wild and domestic rats: Origins of animal psychology revisited}

\author{
ROY T. BAMBER* and ROBERT BOICE \\ University of Missouri, Columbia, Mo. 65201
}

Ten wild and 10 domesticated rats were run in a 4 -alley Lashley maze with food as a reward. Domesticated rats learned the maze in fewer trials and less time, but did not make significantly fewer errors. Domesticated animals were judged more active $b c$ th by an index of activity and by observation. It was concluded, contrary to popular belief, that domesticated rats need not be considered degenerate in their maze-learning ability and that their propensity for exploratory behavior is suggestive as one reason for their faster maze learning.

It is curious that origins of the domestic rat have been mysterious to psychologists since the initial use of that ever popular laboratory animal. Small (1901), apparently the first real rat runner, established a lasting precedent in ambiguity: "I cannot find that the white rat is known to exist in the wild state. There is a tradition that it was brought to the Occident from an immemorial existence in China. I am not able to verify this tradition-or disprove it [p. 221]." Donaldson (1924) was largely responsible for providing and popularizing the domestic rat, perhaps brought from Europe (Castle, 1947) and perhaps not (Richter, 1954). Donaldson's suggestion that Rattus rorvegicus was domesticated by 19 th century collectors of rats for rat-killing sports remains in vogue for lack of a better speculation.

Curious, too, that origins of the primal apparatus for studying rat behavior, the maze, have remained obscure. It seems likely that one unpublicized origin of the popular maze concerns a device used by the Christian Church to replace the crusades as journeys of penance; labyrinthine mazes were used as models for miniature pilgrimages in place of longer and more tedious journeys previously imposed on penitents (Matthews, 1970). By the turn of the 20th century, the maze had become merely a common game and the rat a cooperative penitent for psychology's theoretical crusades.

But while the rat was to persist as a research staple, the labyrinth maze has gone the way of simpler mazes and goalboxes sans mazes. The two decades following the founding of the first animal laboratories at Clark and at Harvard in 1899 (Warden \& Warner,

*Reprints: R. T. Bamber, 209 McAlester Hall, University of Missouri, Columbia, Missouri 65201.
1927) evidenced a positive attitude toward the labyrinthine maze of the Hampton Court garden variety. Hubbert (1915), a student of $J$, B. Watson, used rats because they "are easier to breed, handle, and care for in large numbers than any other small mammal" and used a complex maze because "it is generally conceded that the rat is preeminent among animals in his ability to thread a labyrinth [pp. 4-5].",

Ten years later, criticisms of the old-fashioned labyrinth were mounting. Hall \& Ballachey (1932) argued the open-field test as an alternative because it was less teleological so that the rat would be less "forced to behave according to the purposes of the experimenter [p. 1]." Chief among the proponents of change was C. P. Stone, who advocated a multiple discrimination box in which speed of movement of the rat was not critical (1928a). He surmised, however, that the old maze was "quite satisfactory as a device for acquainting students with the technique of animal experimentation $[1928 b$, p. 517]." Skinner (1930), who was to be a leader in the retreat from mazes, showed the dubious attitude of that time toward mazes in stating that to use the maze to demonstrate the inheritance of learning ability would be "an insuperable difficulty [p. 345].",

By and large, the early maze studies have had little lasting effect on thinking about rat learning. A notable exception is one aspect of the study by Small (1901). Small used both wild and domestic rats, since there was some question as to which would be useful Ss. It does not seem surprising now that the wild rats were uncooperative and did not perform well compared to the domestic rats. Small concluded, however, that the learning ability of the two kinds of rats was probably equivalent. The sequel to this study is Stone's (1932) comparison of wild and domestic rats in a four-alley Lashley maze. Stone's results mirrored Small's; the wild rats were not trained, while the domestic rats were. ${ }^{1}$ But Stone concluded that the wild rats might "actually possess greater learning ability [p. 50]." These two studies are the experimental basis for the traditional belief that the domestic rat is degenerate and has suffered a fall in learning ability compared to the wild rat (e.g., Robinson, 1965; Lockard, 1968).

A number of recent studies (e.g., Boice, 1968, 1970, 1972; Price, 1972) contradict tradition; they suggest that the domestic rat is superior in learning ability to the wild rat. The obvious problem with these recent comparisons is that in each, it could be argued, the performance of wild rats might have been diminished by problems of emotionality and unreasonable learning tasks. When the learning task is made simple and seemingly compatible with the wild rat's natural response style (Bolles, 1970 ), there is no difference in acquisition by wild or domestic rats (Hughes \& Boice, 1972). Tests of other behaviors such as maternal success in captivity also suggest that differences between wild and domestic rats are minimal in many respects. In all, there is no suggestion of a degeneration of learning ability in domestic rats. Still doubts remain as to whether the optimal test has been applied. What if the comparison employed a learning task more like the natural burrow systems used by wild rats?

This was, in fact, a rationale for the original studies of Small, who assumed that the learning task should conform to the psychobiology of the animal (Shettleworth, 1971). He noted that "An animal should be made to do difficult things only in the line of its inherent abilities [Small, 1900, p. 133]." Thus, it would appear that the labyrinth method remains a cogent test for this comparison.

The purpose of the present study was to replicate the Stone (1932) study but with methodological revisions to reduce performance/ emotionality problems in wild rats. Six methodological changes were instituted in that effort: (1) The E stood quietly and was not visible to the rat in the maze; (2) the rats were run at their peak activity period between 2200 and $200 \mathrm{~h}$; (3) room illumination was confined to dim bulbs under the maze, which enabled the $\mathrm{E}$ to see the $\mathrm{S}$ through the blue Plexiglas top of the maze; (4) the Lashley maze was modified so that the rat's own living cage served as the goalbox; (5) the goalbox door was designed so as not to catch the rat's 
Table 1

Means and Standard Deviations for an Activity Measure and Various Criteria of Learning for Domestic and Wild Rats

\begin{tabular}{|c|c|c|c|c|c|}
\hline & & $\begin{array}{l}\text { Trials to } \\
\text { Criterion }\end{array}$ & $\begin{array}{l}\text { Minutes } \\
\text { to } \\
\text { Criterion }\end{array}$ & $\begin{array}{c}\text { Errors } \\
\text { to } \\
\text { Criterion }\end{array}$ & $\begin{array}{c}\text { Errors } \\
\text { Per } \\
\text { Minute }\end{array}$ \\
\hline Domestic & $\begin{array}{l}\text { Mean } \\
\text { SD }\end{array}$ & $\begin{array}{l}17.4 \\
4.30\end{array}$ & $\begin{array}{l}40.0 \\
36.69\end{array}$ & $\begin{array}{l}71.8 \\
35.78\end{array}$ & $\begin{array}{r}2.26 \\
.63\end{array}$ \\
\hline Wild & $\begin{array}{l}\text { Mean } \\
\text { SD }\end{array}$ & $\begin{array}{r}28.2 \\
5.94\end{array}$ & $\begin{array}{l}175.2 \\
100.05\end{array}$ & $\begin{array}{r}109.4 \\
45.92\end{array}$ & $\begin{array}{l}.70 \\
.27\end{array}$ \\
\hline \multicolumn{2}{|c|}{ Difference in Means } & $10.8+$ & $135.2 *$ & 37.6 & $1.56 \dagger$ \\
\hline
\end{tabular}

$*_{p}<.01,+p<.001$

tail and to be quiet in operation; and (6) there were no raucous noises such as the door buzzer associated with entering the goalbox for food in Stone's preliminary study.

\section{SUBJECTS}

The 10 wild male rats were adult Rattus norvegicus, trapped from the landfill at Macon, Missouri. They were habituated to captivity for 45 days before testing, since this factor has been shown to facilitate avoidance learning in captives (Boice, 1970). Their body weights ranged from 224 to $358 \mathrm{~g}(\overline{\mathrm{X}}=289.7 \mathrm{~g})$ at the onset of food deprivation.

The 10 domestic rats were albino Rattus norvegicus of Sprague-Dawley descent which weighed $246-399 \mathrm{~g}$ ( $\overline{\mathrm{X}}=$ $353.3 \mathrm{~g})$ at the onset of food deprivation. Thus, domestics were an average of about $22 \%$ heavier, a figure which conforms to expected weight differences between wilds and domestics (Price, 1972).

All Ss were housed individually. APPARATUS

The maze was a four-alley Lashley maze, $150 \times 240 \mathrm{~cm}$, after the diagram and measurements published by Stone (1932). There were three notable changes from the maze as used by Stone: (1) the startbox was made to accommodate a plastic handling box (Tighe, 1965), so that Ss did not have to be handled directly; (2) the goalbox was the rat's home cage, fitted on its side to the maze opening; and (3) the floor, of 1/4-in. mesh hardware cloth, and the top, of translucent blue Plexiglas, permitted observation of the rats when $6 \cdot \mathrm{W}$ bulbs, placed at $58-\mathrm{cm}$ intervals below the alley floors, were on and all room lights were off. 2

\section{PROCEDURE}

All rats were deprived of their normal quantity of food and maintained at $80 \%$ of initial body weight. The rats were removed from their home cages with the handling box when they were weighed. A glass container of five $45-\mathrm{mg}$ Noyes food pellets was then placed into the home cage, positioned as the goalbox. Because wild rats are sometimes reticent with strange food, quantities of Noyes pellets had been placed in small glass ashtrays in the home cages prior to this training. Only one wild rat failed to eat the pellets; he was therefore given a like quantity of Lab Chow in the goalbox.

Rats were run three trials per day; each trial was limited to $30 \mathrm{~min}$ if the rat had not reached the goalbox in that time.

Timing began when the $S$ left the startbox. Errors for each blind alley

The learning criterion was arbitrarily designated as the last trial preceding 10 consecutive errorless trials.

Means and standard deviations of all dependent measures are shown in Table 1. Domesticated rats achieved criterion in significantly fewer trials $(t$ $=4.655, \mathrm{df}=18, \mathrm{p}<.001)$. Heterogeneity of variance was found in the time to criterion comparison ( $F$ $=7.437, \mathrm{df}=9,9, \mathrm{p}<.01)$. A conservative test yielded $t=4.012, \mathrm{df}$ $=9, \mathrm{p}<.01$. Therefore, domesticated rats mastered the maze significantly faster. There was no significant difference between the groups in errors to criterion $(t=2.042, \mathrm{df}=18$, $\mathrm{p}<.10)$. A crude activity measure derived by calculating errors/minute significantly more active, which confirmed subjective impression. Errors/minute were transformed to angles, and this test yielded $t=6.068$, $\mathrm{df}=18, \mathrm{p}<.001$.

\section{DISCUSSION}

The critical result was that the wild rats performed in the maze, all of them reaching the criterion of learning. There were distinct qualitative differences in the performance of wild and domesticated rats. The wild rats were clearly more inactive, as evidenced in the quantitative index (Table 1) and from subjective impression. But this inactivity did not appear to be similar to a "fearfulness" which might have interfered with acquisition of the maze task. When inactive, the wild rats groomed quietly and often appeared to sleep for long periods of time. In no case did domestic rats settle down to rest; they were typically busy exploring the maze, a factor which were recorded.

\section{Means and standard devi} showed that the domestic rats were might have facilitated maze learning (Thorpe, 1963). Even when active, the wild rats were distracted from completing the maze task by escape attempts and not by freezing and crouching as reported by Stone (1932).

The indices of maze acquisition generally resemble recent comparisons of learning in wild and domestic rats (e.g., Boice, 1968, 1970, 1972; Price, 1972); performance was superior in laboratory rats. This was clearly the case in measures of trials to criterion and time to criterion (Table 1 ).

Perhaps the commonality in performance between the two kinds of rats is suggested in the measure of errors to criterion. While the wild rats did commit a mean of nearly 40 more errors before reaching criterion, that difference from the mean of 71.8 by domestic rats is not statistically significant. However, even a heretical attempt to prove the null hypothesis would not conceal the basic finding of this study that domestic rats were superior maze learners.

In sum, this is apparently the first successful comparison of wild and domestic rats in a complex maze. ${ }^{3}$ Unlike Small (1901) and Stone (1932), the wild rats were induced to learn the maze. And unlike Stone, there is no reason here to suppose that wild rats possess a greater learning ability than domestic rats. Finally, there is still no evidence to support the popular belief (Robinson, 1965; Lockard, 1968) that domestication of the rat has induced a degeneration of learning ability. REFERENCES

BOICE, R. Conditioned licking in wild $F_{1}$ and domestic Norway rats. Journal of Comparative \& Physiological Psychology, 1968, 66, 796-799.

BOICE, R. The effect of domestication on avoidance learning in the Norway rat. Psychonomic Science, 1970, 18, 13-14.

BOICE, $R$. Some behavioral tests of domestication in Norway rats. Behaviour, 1972 , in press.

BOLLES, R. C. Species-specific defense reactions and avoidance learning. Psychological Review, 1970, 77, 32-48.

CASTLE, W. E. The domestication of the rat. Proceedings of the National Academy of Science, 1947, 33, 109-117.

DONALDSON, H. H. The rat. Philadelphia: Wistar Institute, 1924.

HALL, C., \& BALLACHEY, E. L. A study of the rat's behavior in a field: A contribution to method in comparative psychology. University of California Publications in Psychology, 1932, 6, 1-12.

HUBBERT, H. B. The effect of age on habit formation in the albino rat. Behavior Monographs, 1915, 2, 1-55.

HUGHES, C. W., JR. \& BOICE, R. Domestication and avoidance learning in the Norway rat: Effects of handling, directionality, sophistication, and shock intensity. Paper presented at the meeting of the Missouri Psychological Association, St. Louis, Spring 1972.

LOCKARD, $R$. B. The albino rat: A defensible choice or a bad habit? American Psychologist, 1968, 23, 
$734-742$.

MATTHEWS, W. H, Mazes and labyrinths. New York: Dover, 1970.

PRICE, E, O. Domesticatiun and early experience effects on escape conditioning in the Norway rat. Journal of Comparative \& Physiological Psychology, $1972,79,51-55$.

RICHTER, C. P. The effects f domestication and selection on the behavior of the Norway rat. Journal of the National Cancer Institute, 1954, 15, 727-738.

ROBINSON, R. Genetics of the Norway rat. Oxford: Pergamon Press, 1965.

SHETTLEWORTH, S. J. Constraints on learning. In D. S. Lehrman, R. Hinde, and E. Shaw (Eds.), Advances in the study of behavior. Vol. 4. New York: Academic Press, in press.

SKINNER, B. F. On the irheritance of maze behavior. Journal of General Psychology, $1930,4,342-346$.

SMALL, W, S, An experimental study of the mental processes of the rat. American Journal of Psychology, 1900, 11, 133-165.
SMALL, W. S. Experimental study of the mental processes of the rat. II. American Journal of Psychology, 1901, 12, 206-239.

STONE, C. P. A multiple discrimination box and its use in studying the learning ability of rats: I. Reliability of scores. Journai of Genetic Psychology, 1928a, 35, 557-573.

STONE, C. P. The reliability of rat learning scores obtained from a modified Carr maze. Journal of Genetic Psychology, $1928 \mathrm{~b}, 35,507-521$.

STONE, C. P. Wildness and savageness in rats of different strains. In $\mathrm{K}$. S. Lashley (Ed.), Studies in the dynamics of behavior. Chicago: University of Chicago Press, 1932. Pp. 3-55.

THORPE, W. H. Learning and instinct in animals. (2nd ed.) London: Methuen, 1963.

TIGHE, T. J. A handling device for small animals. Journal of the Experimental Analysis of Behavior, 1965, 8, 261-262.

WARDEN, C. J., \& WARNER, L. H. The development of animal psychology in the United States during the past three decades. Psychological Review, 1927, 43, 196-205.

\section{NOTES}

1. Stone did find that wild $X$ domestic hybrids learned the maze better than did domestic rats, probably the result of heterosis (hybrid vigor). This finding is sometimes misrepresented (e.g., Robinson, $1965)$ as evidence that wild rats outperformed domestic rats in Stone's study.

2. This third innovation is copied directly from mazes designed by F. A. Logan at the University of New Mexico.

3. Stone (1932) mentioned that two of his students and names-to-be, Harlow and Miles, were completing an improved version of that study. Harlow (personal communication, 1968) provides only this information: "Unfortunately, the study was not published." 